improved proprioception between digits of the same hand compared with that between digits of opposite hands. The technique is easily mastered if attention is paid to pacifying the infant and maintaining a relaxed posture. Pressure applied to the abdomen should be steady but not excessive so that the infant remains quiet throughout the examination. The result of the examination is inconclusive in a small percentage of cases.

False-positive clinical diagnosis of a renal anomaly occurred in 20 of our infants; in 12 mild inequality of renal size gave the impression of mild unilateral renal enlargement. Most of these unconfirmed examples of renal enlargement occurred in the earlier part of the study. As we became more experienced mild inequality of renal size was accepted as normal. False-negative diagnoses did not come to our attention in the same hospital during or after the study. A few infants with potentially palpable renal anomalies were probably missed.

Table II compares the incidence of the different anomalies in this and two other series. ${ }^{12}$ Our overall incidence of $0.5 \%$ is similar to that of Museles et al, ${ }^{1}$ and in both studies the commonest anomalies were unilateral agenesis, pelvic ectopia, and horseshoe kidney. Hydronephrosis was relatively common in our series and that of Sherwood $e t a l^{12}(0.06 \%$ and $0.07 \%$ respectively) but was not diagnosed in the series of Museles et al.

In practice the deeply palpated renal anomaly is mostly undetected in the newborn period and is diagnosed as a result of complications occuring later in childhood or in adult life. Examination of the urine gave mainly negative results immediately after birth, especially in infants with the less easily palpated renal anomalies and therefore seems not to be a useful screening procedure in this age group. Retrospective clinical and necropsy studies $^{2-9}$ show that pyelonephritis, calculi, hypertension, hydronephrosis, nephroblastoma, and renal adenocarcinoma are associated with unilateral agenesis or hypoplasia, ectopia, malrotation and horseshoe kidney. For example, in 31 patients with unilateral agenesis ${ }^{5}$ eight had hydronephrosis (without calculi), six had calculi, two had isolated urinary infection, and one had pain from ectopia of the single kidney, leaving 14 free of complications. Another series of 51 patients with horseshoe kidney $^{6}$ included only 14 patients without complications; and 20 cases of nephroblastoma in a horseshoe kidney have been reported. ${ }^{9}$

Follow-up in the newborn infant with a renal anomaly should therefore be directed towards detecting complications by urine examinations, blood pressure measurements, and regular abdominal palpation, with further investigation as required. Until prospective follow-up of these anomalies is undertaken from the newborn period, the numerical risk of complications will remain uncertain.

\section{References}

${ }^{1}$ Museles, M, Gaudry, C L, jun, and Bason, W M, Pediatrics, 1971, 47, 97.

2 Berant, M, Jacob, E T, and Pevzner, S, Journal of Pediatric Surgery, 1975, $10,555$.

${ }^{3}$ Campbell, M F, and Harrison, J H (editors), Urology, 3rd edn, vol 2, p 1419. Philadelphia, Saunders, 1970.

4 Campbell, M F, and Harrison, J H (editors), Urology, 3rd edn, vol 2, p 1460. Philadelphia, Saunders, 1970.

5 Dees, J E, fournal of Urology, 1960, 83, 550.

6 Glenn, J F, New England fournal of Medicine, 1959, 261, 684.

7 Langworthy, H T, and Drexler, L S, fournal of Urology, 1942, 47, 776.

${ }^{8}$ Lee, H P, fournal of Urology, 1949, 61, 333.

9 Shashikumar, V L, et al, fournal of Pediatric Surgery, 1974, 9, 185.

${ }^{10}$ Yearbook of Pediatrics, 1972, ed S S Gellis, p 226. Chicago, Yearbook Medical Publishers, 1972.

11 Campbell, M F, Pediatric Clinics of North America, 1955, 2, 653.

12 Sherwood, D W, et al, Pediatrics, 1956, 18, 782.

\title{
Pseudomonas aeruginosa infections associated with use of contaminated medicaments
}

\author{
ROSAMUND M BAIRD, R A SHOOTER
}

British Medical fournal, 1976, 2, 349-350

\section{Summary}

Pseudomonas aeruginosa was recovered from three hospital-prepared medicaments being used on the wards. Sixty-six patients were studied to observe the effect of using these contaminated medicaments. Ps aeruginosa was recovered from 29 patients; in five the strains recovered bore a close resemblance to strains previously isolated from the contaminated medicaments.

\section{Introduction}

Pharmaceutical products made in the hospital may become contaminated with strains of Pseudomonas aeruginosa from the pharmacy environment. ${ }^{1}$ In one hospital pharmacy medicaments

Department of Medical Microbiology and Pharmacy, St Bartholomew's Hospital, London EC1A 7BE

ROSAMUND M BAIRD, PHD, principal pharmacist

R A SHOOTER, FRCP, FRCPATH, professor of medical microbiology contaminated with Ps aeruginosa were inadvertantly issued to the wards, and we attempted to trace the routes by which patients may have acquired strains of Ps aeruginosa from these medicaments.

\section{Methods}

Nine wards of the hospital were examined over two months. Three medicaments in the wards (pine disinfectant, chlorxylenol disinfectant, and a handcream), the ward environment, and the patients were examined for Ps aeruginosa. Patients examined included those with known pseudomonas infections, patients in adjacent beds to those with infections, and patients with bedsores or open wounds. The disinfectants were used in the wards for cleaning floors, lavatories, sinks, and baths. The handcream was used only by the nurses.

\section{CULTURAL METHODS}

Medicaments-1 ml or $1 \mathrm{~g}$ was incubated overnight at $37^{\circ} \mathrm{C}$ in $20 \mathrm{ml}$ of nutrient broth containing $4 \%$ Lubrol $\mathrm{W}$ and then subcultured to $0.03 \%$ cetrimide agar.

Environmental sites-Mops, buckets, cloths, and handmops were sampled with moistened swabs, incubated overnight in nutrient broth, and then subcultured to cetrimide agar. 
Patients-Survey 1: swabs moistened in nutrient broth were taken from the external ear, umbilicus, and from some bedsores of 53 patients, and mid-stream urine specimens and some sputum specimens were also collected. Survey $2:$ the above specimens were collected from 23 patients, 10 of whom had been examined in survey 1 . In addition, swabs were taken from the axillae, area beneath each breast, groin, buttocks, popliteal space of each knee, skin between the toes, and hands. All swabs were incubated overnight at $37^{\circ} \mathrm{C}$ in nutrient broth, then subcultured to cetrimide agar. Urine samples were cultured directly on to nutrient agar. Sputum samples were digested with pancreatin(Oxoid) and then plated directly on to cetrimide agar. Hands were immersed in $100 \mathrm{ml}$ of nutrient broth and rinsed several times. The broth was cultured directly, the remainder being incubated overnight and then subcultured to cetrimide agar.

\section{IDENTIFICATION AND TYPING OF PS AERUGINOSA}

Ps aeruginosa was identified either by pyocyanin production or by biochemical methods, as described." Strains were typed with a combination of serological and bacteriophage typing techniques.

\section{Results}

The table gives details of the samples taken, the number from which Ps aeruginosa was isolated, and the coding of these strains, where appropriate. The pharmacy had been examined twice before ${ }^{1}$ : in the first survey only one strain of Ps aeruginosa was found; in the second, a year later, several new strains were isolated as well as the original strain. In four of the five pharmacy medicaments found to be contaminated with Ps aeruginosa, a strain indistinguishable from at least one of the environmental strains was isolated. Three of these medicaments $(1 / 20$ dilutions of pine and chlorxylenol disinfectants, and a handcream containing propyl and methyl hydroxybenzoates) were widely used on the wards.

Summary of samples taken in hospital and distribution of Ps aeruginosa

\begin{tabular}{|c|c|c|c|c|}
\hline $\begin{array}{l}\text { Site of } \\
\text { isolation }\end{array}$ & $\begin{array}{c}\text { No of } \\
\text { samples }\end{array}$ & $\begin{array}{c}\text { No of } \\
\text { samples } \\
\text { from which } \\
\begin{array}{c}P s \\
\text { aeruginosa } \\
\text { was isolated }\end{array}\end{array}$ & $\begin{array}{c}\text { Total No of } \\
\text { isolates of } \\
P s \\
\text { aeruginosa }\end{array}$ & $\begin{array}{c}\text { Coding of } \\
\text { strains }\end{array}$ \\
\hline $\begin{array}{l}\text { Pharmacy environment: } \\
\text { Survey } 1 \\
\text { Survey } 2 \\
\text { Pharmacy medicaments } \\
\text { Ward medicaments } \\
\text { Ward environments } \\
\text { Patients: }\end{array}$ & $\begin{array}{l}49 \\
35 \\
27 \\
31 \\
38\end{array}$ & $\begin{array}{l}16 \\
20 \\
19 \\
24 \\
13\end{array}$ & $\begin{array}{l}16 \\
22 \\
21 \\
32 \\
14\end{array}$ & $\begin{array}{l}\text { A } \\
\text { A, B, C, D, E } \\
\text { C, D, E, F, NT } \\
\text { C, D, E, F, NT } \\
\text { E, F, and others }\end{array}$ \\
\hline $\begin{array}{r}\text { Survey } 1 \\
\text { Survey } 2\end{array}$ & $\begin{array}{l}53 \\
23\end{array}$ & $\begin{array}{l}22 \\
16\end{array}$ & $\begin{array}{r}36 \\
100\end{array}$ & $\begin{array}{l}\mathrm{D},{ }^{*} \mathrm{~F}, \text { and others } \\
\mathrm{C}, \mathrm{D}, \mathrm{E} \text {, and others }\end{array}$ \\
\hline
\end{tabular}

NT $=$ Non-typable by bacteriophage and serological methods.

*Strain isolated from two patients.

\begin{tabular}{c|c|l}
\hline Code & Serotype & Phage pattern \\
\hline A & 6 & 44 F8 109 1214 \\
B & 10 & M6 \\
C & 11 & NT \\
D & PA & NT \\
E & PA & 119X M6 \\
F & NT & 119X M6 \\
\hline
\end{tabular}

Ward medicaments-At least one of the three medicaments concerned was found in each ward. Ps aeruginosa was isolated from 24 of the 31 products examined: 17 of the 20 pine disinfectants; 4 of the 6 chlorxylenol disinfectants; and 3 of the 5 handcreams. Several strains were found to be very similar to strains previously isolated from medicaments in the pharmacy and from the pharmacy environment.

Ward environments - In six wards Ps aeruginosa was isolated from 13 of the 38 items of cleaning equipment. Several different strains were found and two of these corresponded closely to strains previously found in the contaminated disinfectants. Non-typable strains were also isolated; on several occasions similar strains had also been found in the ward and pharmacy medicaments.

Patients-The first survey was carried out over one month during which the 53 patients were examined once. Ps aeruginosa was isolated from one or more sites in the nine patients with clinical pseudomonas infections and from 13 patients who were apparently unaffected by this organism. Strains of Ps aeruginosa isolated from three patients in different wards bore a close resemblance to strains previously found in the contaminated medicaments. These were isolated from the external ear of a non-infected patient, from an infected bedsore of a second patient, and from the urine sample of a third patient with an infected bedsore. Two of the three strains concerned were polyagglutinable with a non-typable bacteriophage typing pattern. In the second survey $P s$ aeruginosa was isolated from 16 out of 23 patients, five of whom had clinical pseudomonas infections. Strains of Ps aeruginosa recovered from three patients (one of whom had already been examined) again bore a close resemblance to strains previously isolated from the contaminated medicaments. The strain from the umbilicus of one patient was very similar to those that had been found in the handcream and in a bottle of pine disinfectant. A strain isolated from the groin and bedsores of another patient corresponded closely to a strain found in several of the contaminated disinfectants. The third patient (the patient with a urinary tract infection in survey 1) still seemed to be infected by the same polyagglutinable strain of Ps aeruginosa.

Clinical details of patients in surveys 1 and 2-Nine of the 10 patients with clinical pseudomonas infections had previously been given broadspectrum antibiotics; three had also been taking steroid drugs and one had had antimetabolite drugs prescribed. Of the 19 patients without infections from whom Ps aeruginosa was isolated 15 had previously been given broad-spectrum antibiotics and three had also been taking steroids. Five of these patients were diabetics. The five patients (one of whom was examined twice) from whom medicament strains of $P s$ aeruginosa were isolated had all taken broad-spectrum antibiotics previously and all had had clinical infections within the past two months, although not all of these were due to pseudomonas. Four of these five patients, average age of 76 , died within a month of their examination.

\section{Discussion}

The typing results suggested that strains of Ps aeruginosa could survive in the three medicaments for long periods and that these strains could also be recovered from the ward and some of the patients. Strains from five of the 29 patients were shown to be very similar to strains previously found in the contaminated disinfectants and handcream. In three of the five patients these strains were isolated from infected sites.

In both surveys there appeared to be much cross-infection within the wards and between wards. Recovery of Ps aeruginosa from patients appeared to vary from patient to patient; in some cases the organism was isolated from only one or two sites, sometimes associated with a clinical infection; in other cases almost all skin sites examined yielded $P s$ aeruginosa.

Ps aeruginosa was recovered from a surprising number of patients who showed no evidence of clinical infection with this organism. This contrasts with the results of a small control study carried out at St Bartholomew's Hospital, where similar groups of patients were examined; there Ps aeruginosa was not found in the absence of clinical infection. ${ }^{3}$ One possible explanation for the differences between these two hospitals might have been the use of contaminated medicaments.

The continued use of contaminated medicaments may build up a reservoir of infection in a ward, which may act as a potential threat to patients, particularly those who are elderly, debilitated, or taking broad-spectrum antibiotics, antimetabolite drugs, or steroid drugs.

We thank Dr J A Child for arranging the work on the wards, Dr M T Parker, director of the Cross Infection Reference Laboratory of the Public Health Laboratory Service, for typing strains of Ps aeruginosa, and the Department of Health for a grant in support of this work.

\section{References}

1 Baird, R M, Brown, W R L, and Shooter, R A, British Medical fournal, $1976,1,511$.

2 Shooter, R A, et al, Lancet, 1969, 1, 1227.

3 Baird, R M, PhD Thesis, University of London, 1975. 